DOI: 10.20472/IAC.2018.040.010

\author{
MAN-LING CHANG \\ National Chung Hsing University, Taiwan
}

\title{
CAN ETHICAL LEADERSHIP PROMOTE EMPLOYEES' PROACTIVE BEHAVIORS?
}

\begin{abstract}
:
Repeated scandals and ethical meltdowns from private and public organizations have sparked increased interests in studying positive influences of ethical leadership, defined as the demonstration of normatively appropriate conduct and the promotion of such conduct to employees through two-way communication and reward. However, a few researchers concerned the potential danger of using ethical leadership. These concerns lead to a curiosity that whether ethical leadership constrains or promotes employee's proactive behavior. In response to this curiosity and recent call for positive psychology approach, this study attempts to explore the influence of ethical leadership on employee proactive behavior and the indirect effect of psychological capacity (PsyCap) on the relationship. Drawn from social learning theory and conservation of resources theory, this study establishes a mediated hypothesis. Three waves of survey separated by two weeks collected 248 employees working in 49 public sectors in Taiwan. A two-level mediation model tested by Mplus shows that ethical leadership brings into play its positive influence on employee proactive behaviors including taking charge, voice, individual innovation, problem prevention. PsyCap serves as an effective mediator in the relationship between ethical leadership and proactive behaviors. This study contributes to the literature by showing additional benefits of ethical leadership and PsyCap.
\end{abstract}

\section{Keywords:}

Ethical leadership, psychological capacity, proactive 